九州大学学術情報リポジトリ

Kyushu University Institutional Repository

\title{
Comparison of COFECHA and TSAPWIN from Dendroclimatology for Climate Change and Taiwan Fir (Abies kawakamii) Growth Pattern in Alpine Central Taiwan
}

\section{Chan, Ming-Hsum}

Department of Forestry and Natural Resources, College of Agriculture, National Chiayi University

$\mathrm{Hu}$, Shin-Te

Department of Forestry and Natural Resources, College of Agriculture, National Chiayi University

Lin, Han Chien

Department of Wood Based Materials and Design, College of Agriculture, National Chiayi University

Fuj imoto, Noboru

Laboratory of Wood Material Technology, Division of Sustainable Bioresources Science, Department of Agro-environmental Sciences, Faculty of Agriculture, Kyushu University

https://doi.org/10.5109/26170

出版情報: 九州大学大学院農学研究院紀要. 58 (1)，pp.115-123，2013-02. Faculty of Agriculture， Kyushu University

バージョン :

権利関係 : 


\title{
Comparison of COFECHA and TSAPWIN from Dendroclimatology for Climate Change and Taiwan Fir (Abies kawakamii) Growth Pattern in Alpine Central Taiwan
}

\author{
Ming-Hsun CHAN ${ }^{1 *}$, Shih-Te HU' ${ }^{1}$, Han Chien LIN $^{2}$ \\ and Noboru FUJIMOTO ${ }^{3}$ \\ Laboratory of Wood Material Technology, Division of Sustainable Bioresources Science, \\ Department of Agro-environmental Sciences, Faculty of Agriculture, \\ Kyushu University, Fukuoka 812-8581, Japan \\ (Received October 31, 2012 and accepted November 8, 2012)
}

\begin{abstract}
Many tree ring researches have worldwide revealed that climate change influence tree growth pattern in alpine tree-line, but it is still lack of these research in Taiwan. From central Taiwan Mt. Hehuan alpine tree-line Taiwan fir (Abies kawakamii H.) dendroclimatic analysis, we found the relationships of ring width and BAI growth with climate change in 1953-2010. Tree ring width and BAI growth were highly significant correlated to standard chronology, residual chronology and autoregressive chronology, it responded most similar climate signal at the same periods, and tree ring width standard chronology reflected most climate signals. Tree ring width and BAI growth responded temperature decreasing correlation in February, March, April of early spring, it reflected that the later summer temperature increasing correlation in August, September and October, at the same time monthly temperature and season temperature reflect synchrony of most part. Tree ring width and BAI growth reflected monthly accumulated precipitation increasing correlation in January and March, and reflected August and November monthly accumulated precipitation decreasing correlation. It is understand that early spring low temperature with increasing precipitation and later summer high temperature with decreasing precipitation promoted Taiwan fir to grow. The average temperature of recent 60 year later summer (August, September, and October) has increasing trend $1^{\circ} \mathrm{C}$. The increasing trend of BAI growth was as same as mean temperature in later summer, it had a high linear correlation. Later summer temperature increasing and warming promoted to grow, the research found that the increasing temperature in early spring would suppress the growth. And, the relationship establishment of tree ring width and BAI growth, climate change would help to understand how climate warming influence tree growth pattern in alpine forest tree-line.
\end{abstract}

Key words: Climate change, Taiwan fir (Abies kawakamii H.), Dendroclimatology, Tree ring analysis, Basal area increment (BAI), Growth pattern

\section{INTRODUCTION}

Under different environments, trees has recorded signals of a variety of types (Schweingruber, 2007). The ring width change implies climate information and the growing season. Through analyzing tree ring, we can understand how climate change affects the growth of trees. Studying the relationship between limiting factor and ring width is able to reconstruct the weather in the past or predict the future weather.

The average temperature has increased $0.8^{\circ} \mathrm{C}$ from 1866 in global (Bluemle, 1999). Climate change and global warming cause lots of effect in global. With the rise of temperature, forest vegetation is moving high latitude and high altitude. The tree-line of alpine forest was immigrating upward on altitude (Kullman, 1998).

Taiwan fir (Abies kawakamii H.) is the highest forest in Taiwan (Flora of Taiwan, 1994). Climate is the

\footnotetext{
1 Department of Forestry and Natural Resources, College of Agriculture, National Chiayi University, Chiayi, Taiwan, ROC

Department of Wood Based Materials and Design, College of Agriculture, National Chiayi University, Chiayi, Taiwan, ROC Laboratory of Wood Material Technology, Division of Sustainable Bioresources Science, Department of Agroenvironmental Sciences, Faculty of Agriculture, Kyushu University

* Corresponding author (E-mail: mhchan@mail.ncyu.edu.tw)
}

main factor that affects vegetation distributes in the longterm. Temperature and precipitation were the most effective (Walther, 2003). Taiwan fir grows on the timberline, where temperature and precipitation are growthlimiting factors. Because the growing of Taiwan fir is controlled by the growth-limiting factors, by studying the ring width growth, the study tried to understand how climate affects trees. The mean sensitivity of Taiwan fir is around 0.14 , it is a fine material for studying the climate response (Tsou, 1998).

Crossdating aims to synchronize growth ring series by aligning patterns in ring width (Pilcher, 1990). To facilitate the crossdating process, numerous methodologies and computer software have been developed. Computer software were such as COFECHA (Holmes, 1983), and TSAPWin (Rinntech, 2009). COFECHA standardizes the raw data of ring width, and provides the correlation test of the whole series and each segments (by default 50-ring). Default standardization include cubic smooth spline (rigidity 32 rings), autoregressive modeling and logarithmic transformation. TSAPWin displays the ring width in line graph, and provides synchrony test of each series. TSAPWin also combines the ring width measurement. With this function, it can easily measure and analyze.

Radial growths of trees were influenced by temperature and precipitation in the cold high tree-line zone, and 
it responsed different in monthly (Wang et al., 2006). The strongest relationships between radial growth and climatic factor are often found at natural latitude and altitude tree-line (Cullen et al., 2001). Basal area increment (BAI) is used in the forest growth and the modeling studies because it provided an accurate quantification of wood production (Rubino and McCarthy 2000). There were lots of research about the ring width and climate response (MacDonald and Case, 1998; Wang et al., 2006; Lloyd and Graumlich, 1997), but there were less researches on BAI and climate response (Renzo and Paola, 2001; Linares et al., 2010). Ring width were compared with temperature but found no linearly respond (Leonelli et al., 2009). BAI might be a better material because it shows the growth pattern of trees.

In this paper, we applied Dendrochronology to crossdating two aid softwares TSPAWin and COFEHA to dating quality test methods, comparing its difference between synchrony test (Glk) and correlation test to crossdating analysis (r value). With visual crossdating, mixed using two test methods were able to get the statistic information about estimating sample missing rings or false rings within trees and between trees. We established BAI chronology by tree ring width chronology, and tested the alpine forest tree-line Taiwan fir growth chronology's sensitivity to climate, comparing the correlation of tree ring width chronology and BAI chronology to the season and month climate data. The study especially focused on the correlation of significant climate change in recent 60 years period (1953-2010) and the growth-climate relationship occurred in Taiwan forest tree-line. At the same time we were also interested in how BAI growths (no standardize) directly reflected the relationship with climate, so we analyzed the linear correlation between alpine forest tree-line Taiwan fir BAI growth responses and the reflection trend of season and month climate. It more clearly shows how recent climate warming change influence alpine forest tree-line Taiwan fir growth.

\section{MATERIALS AND METHODS}

\section{Site description and climate data}

The study site is located near Konankuan at Mt. Hehuan ( $\left.24^{\circ} 9^{\prime} 48^{\prime \prime} \mathrm{N} ; 121^{\circ} 16^{\prime} 3^{\prime \prime} \mathrm{E}\right)$. It is a valley; there is a slope aspect at west and east side. Tree line on the west slope is higher.

According to Köppen climatic classification, the climate on Mt. Hehuan is classified as central alpine cold winter few rain climate zone (GDw). The climate data (monthly average temperature, monthly accumulated precipitation) is collected from Central Weather Bureau Mt. Hehuan automatic weather station. The climate data only wrecord from 1991 to 2010, so we use nearby Alishan weather station (2406 m) and Mt. Jade weather station (3950 m) to estimate climate at Mt. Hehuan from 1953 to 1990 .

The mean annual temperature is $5.35^{\circ} \mathrm{C}$. The highest monthly average maximum temperature from June to September is between 8.6 and $9.7^{\circ} \mathrm{C}$ while the lowest

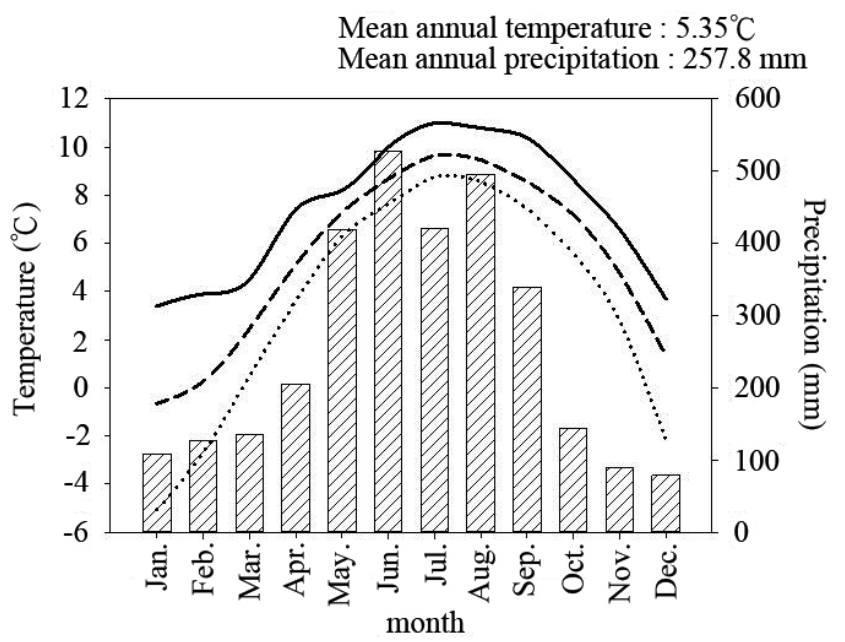

Fig. 1. Mean monthly temperature and mean annual accumulative precipitation of Mt. Hehuan from AD 1953-2010.

Legends —_: Highest temperature; - - - -: Mean temperature; ........ Lowest temperature; Bar: Precipitation

monthly average maximum temperature from December to February is between -0.6 and $1.4^{\circ} \mathrm{C}$. The mean annual accumulated precipitation is $3839 \mathrm{~mm}$ (Fig. 1).

The Rainy season is from May to September (338$700.9 \mathrm{~mm}$ ). The main dry season is from October to next April. Snow season lasts for 3 to 4 months, from late December to early March next year. Most accumulated snow is gathered between Kunyang and Xiaofengkou.

The $\mathrm{pH}$ range of the soil around Konankuan is 4.6 to 5.0 ; it is a strongly acidic soil. The texture is kind of heavy clay, and the percentage of clay particle is above 35\%. The base saturation is very low (less than 5\%). The movement of the organic in the cross section is not obvious but the movement of the iron in soil $\left(\mathrm{Fe}_{\mathrm{p}}, \mathrm{Fe}_{\mathrm{o}}, \mathrm{Fe}_{\mathrm{d}}\right)$ is apparent meaning the alternating wet and dry, and leaching. The main clay minerals still remain 2:1 type minerals Vermiculite, illite and kaolinite. Goethite and lepidocrocite are the two minerals could be found in layer 3Bw (King et al., 1991).

The growing season of Taiwan fir starts from May or June and ends at September or October. It is the highest forest vegetation in Taiwan and establishes pure forest in strong sunshine dry zone at altitude 3100 to $3700 \mathrm{~m}$.

\section{Sampling and collecting}

The sample plot locates on the west slope near Konankuan, the plots altitude is around 2950 to $3000 \mathrm{~m}$ (Fig. 2). It is an ecotones of Taiwan fir and Yushan cane. In 2010, 25 trees were successfully cored using $5 \mathrm{~mm}$ increment borer with total 50 cores. Each sampled tree has been cored two positions at the normal wood. The coring height is about $50-130 \mathrm{~cm}$ above ground (Speer, 2010 ).

\section{Tree ring analysis}

The cores need to be air-dried and stick tight on the core mount using glue. The core were sanded using sand paper with progressively finer grit size (ISO240 to 
ISO600-grit). Ring width was measured with the Velmex measuring system (Serguei, 2003) and the computer software TSAPWin. The subsequent crossdating process is schematized in Fig. 3.

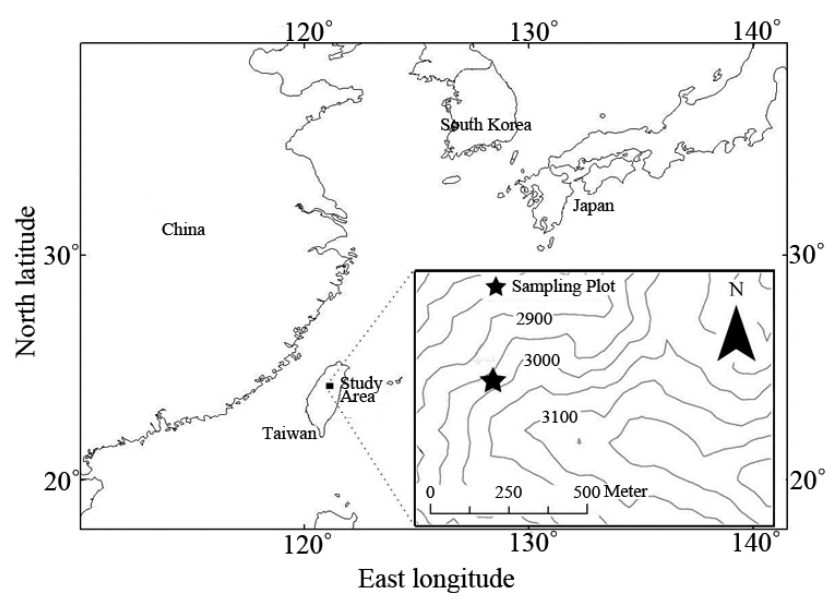

Fig. 2. Contour plots of study area. The study area is located in Hehuan peaks, Nantou county. The sampling plot is set on the west slope of Mt. Shimen. The altitude of the sampling plot is between elevation of 2950 and $3000 \mathrm{~m}$.

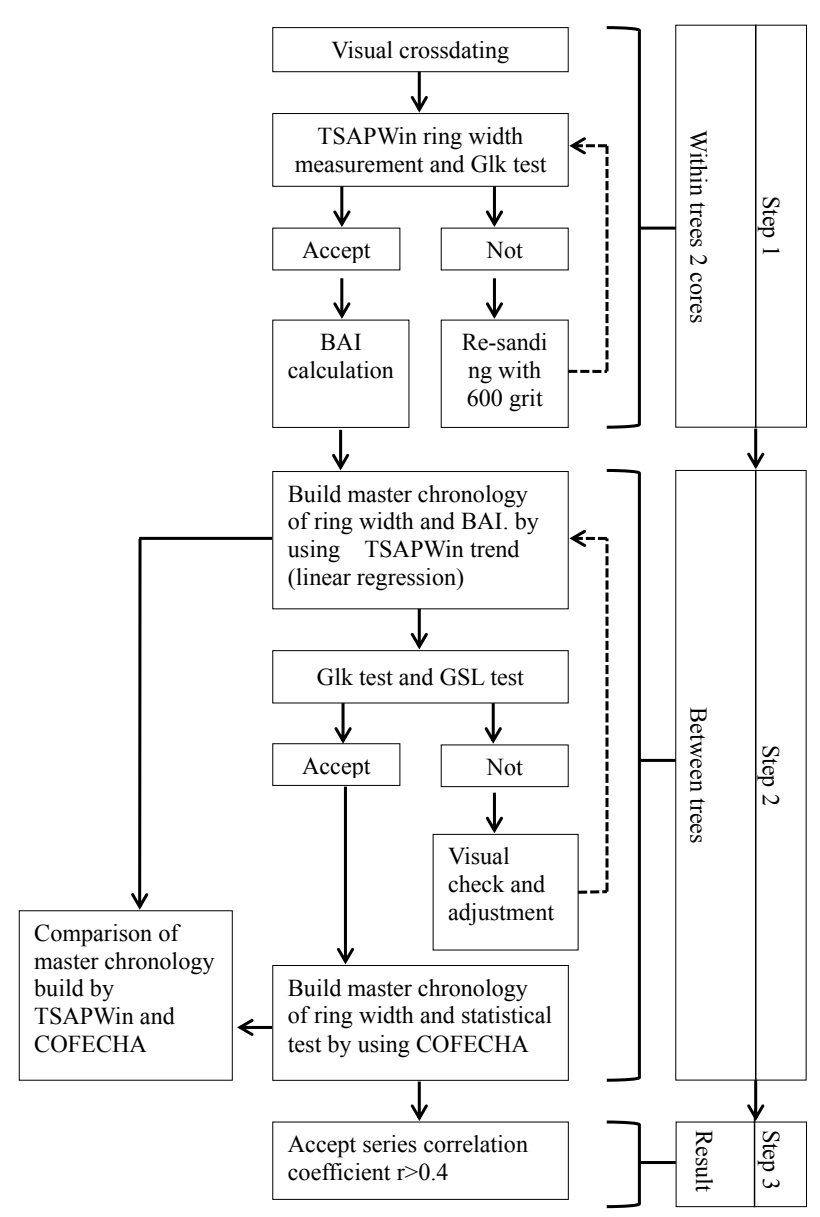

Fig. 3. Flow chart summarizing the stepwise crossdating process. Notes TSAPWin: Computer software; BAI: Basal area increment; Glk: Synchrony test; GSL: Significance of Glk; COFECHA: Crossdating check software.

\section{Ring width measurement}

The ring widths were measured with the Velmex measuring system and the computer software TSAPWin. The device of Velmex measuring system includes Nikon stereomicroscope and a precision of $0.001 \mathrm{~mm}$ measuring stage. Connect the measuring function in TSAPWin to start the measurement.

\section{Crossdating within trees}

TSAPWin synchrony test function is useful to quickly mark wide and narrow alternating marker year. Crossdating within trees according to marker ring and visual dating to adjust missing ring and false ring, and adapt synchrony test Glk value to estimate if crossdating within trees was significance or not. When synchrony was significance, using COFECHA correlation test $r$ value to estimate if significant. If crossdating within trees correlation test was insignificance, adjusting with visual dating or rejected. When crossdating within trees was significance, the individual series enter to crossdating between trees procedure.

\section{Crossdating between trees}

Applying TSAPWin to combine each series become an average master chronology, then proceed TSAPWin synchrony test on each series and master chronology series, especially focus on wide and narrow alternating marker year changing synchrony, because the synchrony of wide and narrow alternating series year position has great contribution to correlation $r$ value.

When each series and master chronology series was significance, through visual dating compare marker year to adjust missing ring and false ring position, then proceed synchrony test, if insignificant then rejected.

Each series which passed synchrony test then using COFECHA correlation test and $r$ value test to examine if each series and master chronology series was significance or not. Each series which through COFECHA correlation test was in significance, using TSAPWin graphic function to inspect master chronology series and using COFECHA to crossdating statistics low correlation segment series, then adjust with visual dating, especially focus on wide and narrow ring alternating marker year change synchrony, if each series after adjustment did not reach correlated significance, then rejected that series.

A useful test in TSAPWin is the synchrony Glk test (Gleichläufigkeit). Glk value is a measure of the similarity between $n$ and $n+1$ year. The total Glk value over all the intervals is a measure of the agreement between the interval trends of two curves, and is expressed as a percentage.

Trending each cores ring width data with linear regression, each series were trend into mean of 0 and display as a line graph. An average of all series was then used to build the master chronology. Then run the consistency between master chronology and the raw data. Significance of Gleichläufigkeit (GSL) is a significant test of Glk value. There are $p<0.05, p<0.01$ and $p<0.001$ three levels, each indicates significance, very significance and extreme significance. The significance value change 
depends on the length of master chronology. The shorter the master chronology is the higher Glk value to reach significant.

COFECHA is a computer software written in ANSI standard Fortran-77 by Richard L. Holmes. first COFECHA appeared in 1982. COFECHA software provides ring width measurement quality control, and can help show problematic segments in output. COFECHA used default 32 years cubic smoothing spline fitting ring width, and used Pearson correlation to calculate r values, that indicate a correlation between two data. If $r$ value is -1.0 , it means completely unrelated, 1.0 means completely related. Master chronology is made by residuals which time series average value is zero, between fit curve predictive value and raw ring width. After building the master chronology, run correlation test between each cores and master chronology. The correlation critical value change depends on the length of segment. The default option is a segment of 50 years and lag 25 years. At this default option, the critical value of $99 \%$ is 0.3281 (Grissino-mayer, 2001). Segments significant if $r$ value larger than 0.3281 .

COFECHA output contains 7 parts. The most important part is part 7. Mean sensitivity is record and is the most important value in tree ring research. Mean sensitivity is the evident level how trees influence by environment and respond to tree ring growth; it's between 0-2. If mean sensitivity is too low, then there are no sensible different between ring width. On the other hand, the high value dramatic change between ring width. The ring width data cannot be analysis if the mean sensitivity is too high or too low, the ideal mean sensitivity is around 0.2.

The advantage of TSAPWin is that it can easily compare 2 cores within trees and display ring width pattern in math graph. COFECHA output printed with statistical data also shows problematic segments that need to adjust. TSAPWin is much easier to adjust problematic segments than COFECHA. Crossdating is the most time spend in tree ring analysis, properly combine TSAPWin graphic display and COFECHA statistical output may find out the problematic segment faster.

\section{Basal area increment}

Calculate BAI using increment area option in TSAPWin. Trend each BAI series into mean of 0 using linear regression. Average all series to build master chronology.

$$
\begin{aligned}
& \left.\pi *\left[\sum_{1}^{i} a\right)^{2}-\left(\sum_{1}^{i-1} a\right)^{2}\right] \\
& \pi \approx 3.14 ; \quad a=\text { radius }
\end{aligned}
$$

\section{Comparison of cross dating check using $r$ value and Glk value}

43 cores were chooses and crossdating check using TSAPWin synchrony Glk test and COFECHA correlation coefficient $r$ test. Using individual series of ring width and BAI and then match with the master chronology.

\section{Standardization of ring width and BAI}

ARSTAN is a computer program using cubic smoothing spline, double detrending procedure and negative exponential to average, index or detrend ring width. Trending ring width pattern or BAI into standard chronology, residual chronology and arstan chronology. Remove non climate factor by standardization. Standard chronology is a chronology that computed of series of tree-ring data that have been detrended by curve-fitting. The residual chronology is produced in the same manner as the standard chronology, but in this case the series averaged are residuals from autoregressive modeling of the detrended measurement series. The pooled model of autoregression is reincorporated into the residual chronology and produces the autoregressive chronology.

When running ARSTAN, there are 20 options to set up. The most important is option 4, option 16 and option 19. In option 4 choose which detrending method to use on first detrending. Option 16 set up segment year and lag year to calculate running $\mathrm{r}$ and expressed population signal (EPS). Option 19 chooses which summary plot to display. ARSTAN can display graph and show regression formula, and also EPS test. EPS is a signal that calculates sample depth. Generally, EPS must higher than 0.85 if researching with climate.

\section{Growth pattern with climate response}

To study ring width and climate factor, we use correlation function and response function. Correlation function are used to calculated simple correlation between ring width and climate factor. Response function describe outer factor effect ring width using multivariate statistical analysis.

DendroClim 2002 is a statistical tool for the analysis of climate and tree growth relationships. Input data for this program are a ring width data and up to three climatic variables, such as temperature and precipitation, for a given number of years. The monthly range can be choose between January of previous year to December of current year, with total 24 months. The result listed correlation larger than 0.1 or smaller than -0.1 . Correlation 0.1 to 0.5 shows positive correlation; correlation -0.1 to -0.5 shows negative correlation; 0 means no correlation.

\section{RESULTS}

\section{Crossdating}

In total 50 cores were extracted from 25 trees and TSAPWin was then used to examine the synchrony between ring series. Once any needed adjustments were performed, series were then entered into COFECHA to identify correlation of these series. Series having a higher correlation than 0.40 were selected to create a reference chronology spanning 100 years beginning from 1910 to 2009.

Using correlation coefficient $r$ test and Glk test to do crossdating check on ring width and BAI comparing the correlation and synchrony between master chronology and individual series (Table 1). The result showed that 
Table 1. Crossdating check using COFECHA (r value) and TSAPWin (Glk \%) software test on ring width and BAI master chronology with individual chronology

\begin{tabular}{|c|c|c|c|c|c|c|}
\hline \multirow{2}{*}{ Crossdating check } & \multicolumn{3}{|c|}{ Ring width } & \multicolumn{3}{|c|}{ BAI } \\
\hline & Mean & Min & $\operatorname{Max}$ & Mean & Min & $\operatorname{Max}$ \\
\hline Correlation coefficient; r value & $0.54 * * 1)$ & $0.40^{* *}$ & $0.66^{* *}$ & $0.55^{* *}$ & $0.40^{* *}$ & $0.71 * *$ \\
\hline Glk (\%) & $72.46 * *$ & $62.45^{*}$ & $81.80 * *$ & $72.35 * *$ & $63.60 * *$ & $81.80 * * *$ \\
\hline
\end{tabular}

1) $* p<0.05 ; * * p<0.01 ; * * * p<0.001$

$\mathrm{N}=43$ cores

both correlation and synchrony reached $p<0.05$ significance and no significant differences between them.

The master chronology and individual chronology of ring width and BAI had high mean $r$ value in correlation, which were respective $0.54,0.55(p<0.01)$, and the correlation coefficient range is $0.40-0.71 \quad(p<0.01)$. There were high mean Glk value in synchrony, which are respective $72.46 \%, 72.35 \%(p<0.01)$, and Glk range 62.45 $-81.8 \%(p<0.05)$. Results indicated that the Taiwan fir group sampled in this study shows a consistent signal. Results from sampling of Taiwan fir on Jade Mountain resulted in a correlation values which ranged from 0.41 to 0.59 and had a mean sensitivity of 0.14 (Tsou, 1998). Compared to results from this study, growth patterns and mean sensitivity of Taiwan fir growing on Mt. Hehuan demonstrate a comparable level.

Comparing synchrony and correlation of the two master chronologies test by two softwares, two chronologies were significant synchronized at $92 \%(p<0.001)$, and

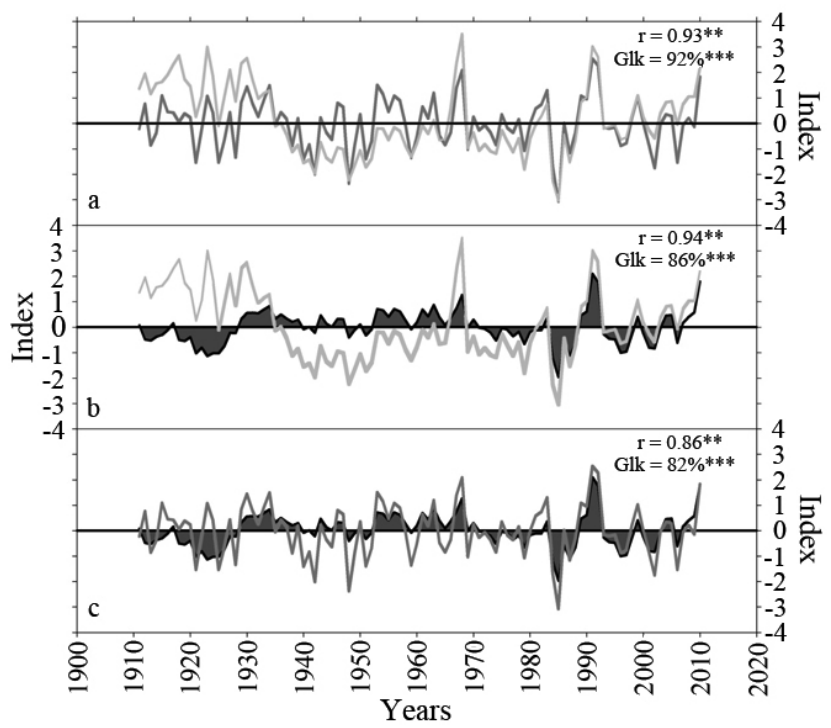

Fig. 4. BAI, TSAPWin and COFECHA ring width master chronology (mean of 0). Line: TSAPWin ring width master chronology (light gray line), COFECHA ring width master chronology (dark gray line), BAI master chronology (black line). Grey-shaded areas are the BAI r-value shows the correlation between two master chronology. GLK value shows the synchronous between two master chronology. The index value of three master chronology is between 4 and -4 . Notes a: Ring width master chronology builds by TSAPWin and COFECHA; b: BAI and ring width master chronology builds by TSAPWin; c: BAI master chronology builds by TSAPWin and ring width master chronology had high correlation coefficient of $0.93(p<0.01)$. The results demonstrated that the master chronologies builded by two softwares are similar (Fig. 4a). Comparing synchrony and correlation of the BAI master chronology with TSAPWin ring width master chronology (Fig. 4b), synchrony results met $86 \%(p<0.001)$, correlation met a high level of 0.94. Comparing to the ring width master chronology build by COFECHA (Fig. 4c), synchrony was $82 \%(p<0.001)$ and having a correlation of 0.86 . These results demonstrated that amplitude of the BAI was consistent with the master chronologies build by TSAPWin and COFECHA. However, amplitude of the BAI master chronology was less extreme.

Tree ring mean width $1.30 \mathrm{~mm}$, the mean ring width decreasing depends on the increasing of tree age, it is shade-intolerant trees; all sample mean sensitivity 0.21 , the mean sensitivity decreasing depends on the increasing of tree age, its tree ring width series variability is less sensitive depends on the increasing of tree age. All express population signal (EPS) was higher than other age stage (Table 2)

Table 2. Tree ring analysis basic data with tree ring width, MS, EPS by 3 age class

\begin{tabular}{ccccc}
\hline $\begin{array}{c}\text { Age class } \\
\text { (year) }\end{array}$ & $\mathrm{N}^{1)}$ & $\begin{array}{c}\text { Ring width } \\
\text { means } \pm \mathrm{sd}^{2)}(\mathrm{mm})\end{array}$ & MS $^{3)}$ & Means EPS \\
\hline $30-40$ & 5 & $1.79 \pm 1.07$ & 0.26 & 0.88 \\
$40-70$ & 18 & $1.66 \pm 0.74$ & 0.21 & 0.91 \\
$70-100$ & 20 & $1.10 \pm 0.73$ & 0.20 & 0.89 \\
All & 43 & $1.30 \pm 0.81$ & 0.21 & 0.92 \\
\hline
\end{tabular}

1) $\mathrm{N}$ : Number of cores

${ }^{2)} \mathrm{sd}$ : Standard deviation

${ }^{3)}$ MS: Means sensitivity

${ }^{4)}$ EPS: Expressed population signal

\section{Ring width and BAI chronology}

ARSTAN constructed tree ring width and BAI 3 chronologies, included a standard chronology (STD), residuals chronology (RES) and autoregressive chronology (ARS). Each chronology indicate a different signal. Indicator values are given for all years between 1910 to 2009 and had an EPS larger than 0.85 (Fig. 5).

Analysis of the 3 ring width chronologies show that they were significantly correlated (Table 3 ). The lowest correlations were the STD and RES (0.835). Regarding $\mathrm{BAI}$, the highest correlation was the ARS and STD 


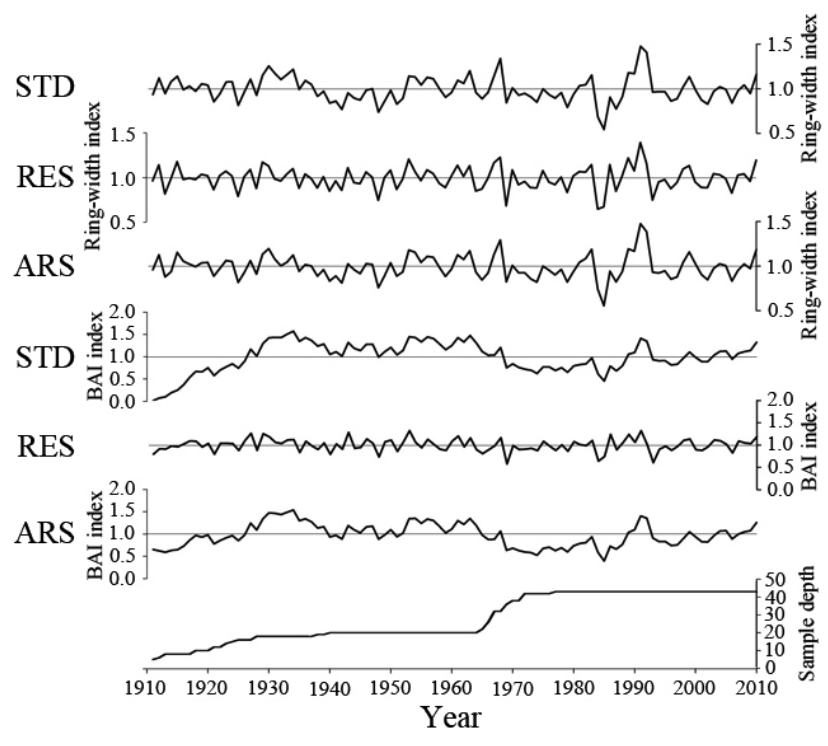

Fig. 5. 3 index chronologies (STD, RES, and ARS) of ring width and BAI, and the sample depth.

Notes STD: Standard chronology; RES: Residuals chronology; ARS: Autoregressive standard chronology

(0.948). The lowest was STD and RES (0.751). STD results showed a long period, and low frequency trend. RES shows a short and high frequency trend and ARS tends to range between the two. Ring width index chronology and sample depth correlation analysis is shown in Figure 5. Results showed that when the sample depth was greatest between 1970 and 2009, synchrony of the 3 index chronology were similar. BAI 3 chronologies and sample depth correlation analysis are shown in Figure 5. Initially, sample depth was low and resultant BAI indicator was near 0 . After 1930, the BAI index increased to 1 and the consistency of the three indicator values was high.

\section{Growth-climate}

Climatic analysis of the 3 chronologies for Ring width and BAI and climate characteristics (monthly average temperature, monthly accumulated precipitation) was performed to understand the influence of the climate on tree growth. And also compare differences climate

Table 3. Correlation matrix of 3 index chronologies on ring width and BAI

\begin{tabular}{lcccccc}
\hline & R. STD $^{3)}$ & R. RES & R. ARS & B. STD & B. RES & B. ARS \\
\hline R $^{1)}$ STD & - & & & & & \\
R. RES & $0.835^{* *}$ & - & & & & \\
R. ARS & $0.961^{* *}$ & $0.889^{* *}$ & - & & & \\
B $^{2)}$ STD & $0.566^{* *}$ & $0.477^{* *}$ & $0.562^{* *}$ & - & \\
B. RES & $0.737^{* *}$ & $0.894^{* *}$ & $0.765^{* *}$ & $0.715^{* *}$ & - & \\
B. ARS & $0.752^{* *}$ & $0.679 * *$ & $0.760^{* *}$ & $0.948^{* *}$ & $0.845^{* *}$ & - \\
\hline
\end{tabular}

\footnotetext{
${ }^{1)} \mathrm{R}$ : Ring width

${ }^{2)} \mathrm{B}$ : Basal area increment (BAI)

${ }^{3)}$ STD: Standard chronology

4) RES: Residuals chronology

${ }^{5}$ ARS: Autoregressive standard chronology
}

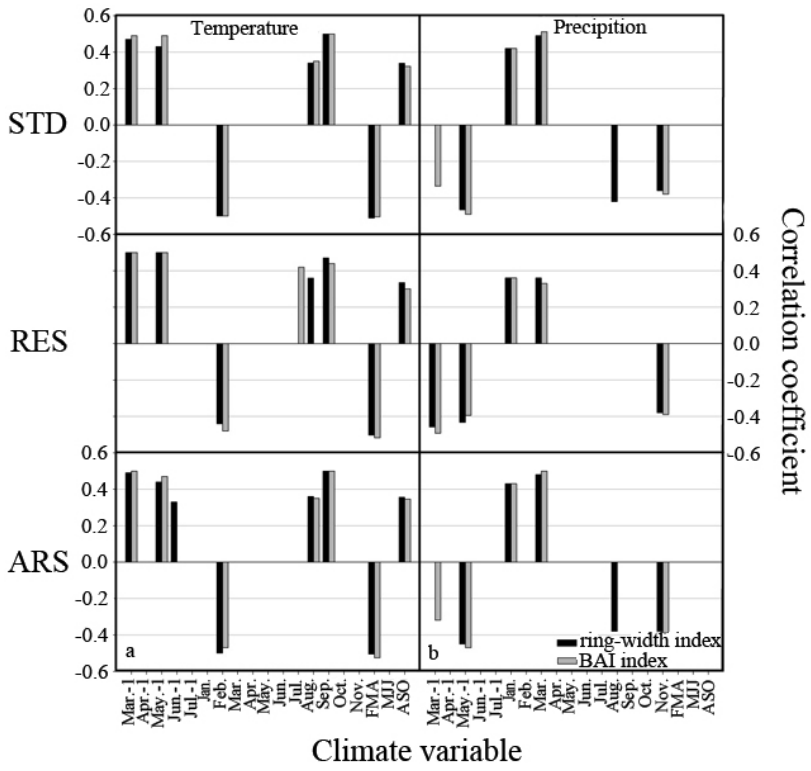

Fig. 6. Correlation coefficient computed between 3 index chronologies and seasonal and monthly variables during the period 1952-2010. Correlation significance was assessed by mean of the $95 \%$ range, and only significant correlation values are showed.

Notes a: Temperature; b: Precipitation; STD: Standard chronology; RES: Residuals chronology; ARS: Autoregressive standard chronology; previous year $(-1)$ : March to July; current year: February to November; Season: FMA, MJJ, ASO

response between ring width and BAI. The climatic analysis over the whole period revealed a strong negative influence of early spring temperatures on tree ring growth, with both the whole spring (February, March, and April) and February temperatures; strong positive influence of autumn temperatures, with both whole later summer (August, September, and October) and August and September temperatures showing the strongest correlation coefficient values (Fig. 6a). In previous year, March and May shows the positive influence of tree ring growth. In precipitation aspect, January and March shows strong positive influence. August and November shows negative influence of tree ring growth. The precipitation of March have the strongest correlation coefficient values (Fig. 6b). In previous year, March and May shows the negative influence of tree ring growth. Ring width and BAI have similar climate response. Ring width 3 chronologies has also similar climate response with BAI 3 chronologies.

\section{DISCUSSION}

The purpose of crossdating is to find missing ring and false ring through the within tree and between tree comparison, and modify tree ring width change to synchrony. TSAPWin and COFECHA are two popular softwares using in crossdating. From the advantage and defect comparison of two software methods in crossdating, we found great difference (Table 4). In usage, TSAPWin can conveniently modify tree ring width information with graphical function, but COFECHA is lack of it. COFECHA has 
Table 4. Comparison of TSAPWin and COFECHA

\begin{tabular}{|c|c|c|}
\hline & TSAPWin & COFECHA \\
\hline \multirow{2}{*}{$\begin{array}{l}\text { Crossdating statistics } \\
\text { Crossdating tes }\end{array}$} & Synchrony Glk value & Correlated r value \\
\hline & $\begin{array}{l}\text { Compare the width change synchrony of } n \\
\text { and } n+1 \text { tree rings }\end{array}$ & $\begin{array}{l}\text { Compare the correlation of tree ring width } \\
\text { change between segments. }\end{array}$ \\
\hline Master chronology composition & $\begin{array}{l}\text { After treated with linear regression, set } \\
\text { means as zero, establish average chronology. }\end{array}$ & $\begin{array}{l}\text { First, fit cubic smoothing spline function with } \\
\text { linear regression, established residual chronol- } \\
\text { ogy. }\end{array}$ \\
\hline Significant interval & $\begin{array}{l}p \text { value }<0.05, \text { significant. } \\
p \text { value }<0.01, \text { very significant } \\
p \text { value }<0.001, \\
\text { Extremely significant }\end{array}$ & $\begin{array}{l}\text { When confidence interval higher than } 99 \% \text {, its } \\
\text { standard value depends on the length of seg- } \\
\text { ment. }\end{array}$ \\
\hline Advantage & $\begin{array}{l}\text { 1. Convenient to modify. } \\
\text { 2. Graphic ability } \\
\text { 3. Can combine with measuring system } \\
\text { 4. Suitable for warm temperate tree species }\end{array}$ & $\begin{array}{l}\text { 1. Result representation complete. } \\
\text { 2. Data clear } \\
\text { 3. Suitable for temperate tree species. }\end{array}$ \\
\hline Defect & 1. Cannot point out problem segment. & $\begin{array}{l}\text { 1. Comparison between segments. } \\
\text { 2. Low-sensitivity tree species cannot make } \\
\text { good correlation. } \\
\text { 3. Inconvenient to modify. }\end{array}$ \\
\hline
\end{tabular}

more complete statistics output, and TSAPWin has simple one. No matter the synchrony test of TSAPWin or the correlation test of COFECHA, both of them has high similarity in the master chronology they produce, if the dating has no many problem appear.

We found that synchrony (Glk value) and correlation ( $\mathrm{r}$ value) analyzed from tree ring and BAI chronology with individual series both showed no significant positive or negative linear correlation (Fig. 7). Glk value and $r$ value are different in calculation. High $r$ value appeared when marker year of 2 series matched. Low $r$ value shows no marker year match or amplitude of the series is too flat. High Glk value appeared when the pattern of tree ring growth matches. The $\mathrm{r}$ value represent better on the extremely wide or extremely narrow rings as known as marker ring, if the marker year match in the series it will have bigger influence to correlation. The difference of $r$ value and Glk value in these aspect would lead to the scatter plot showing not significant correlation. Glk value and $r$ value might have opposite result in series (Fig. 8). High Glk value and low $\mathrm{r}$ value shows the marker year is not matched or the amplitube of the series is too low. High $r$ value and low Glk value shows that marker year is matched but the pattern in the segment is not synchronize.

February temperature shows strong negative influence to tree ring growth of Taiwan fir. If the temperature at February is high, it might cause less rainfall. Early spring precipitation also showed positive influence to the tree ring growth. Early spring is the season start growing. The precipitation play a important role in dry season that effect tree growth. The high temperature in early spring might cause less precipitation, and less precipitation decrease the tree ring growth. The precipitation before growing season is helpful for trees to do photosynthesis. (Watson and Luckman, 2002; Pumijumnong and Wanyaphet, 2006).
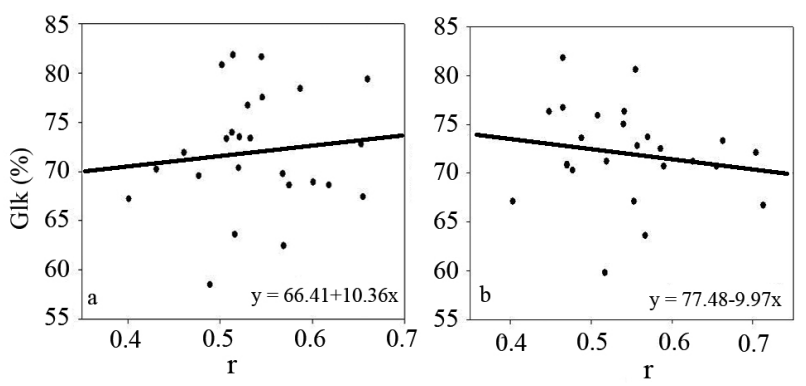

Fig. 7. The scatter plot of $r-$ value and Glk value. Notes a: Ring width; b: Basal area increment (BAI)
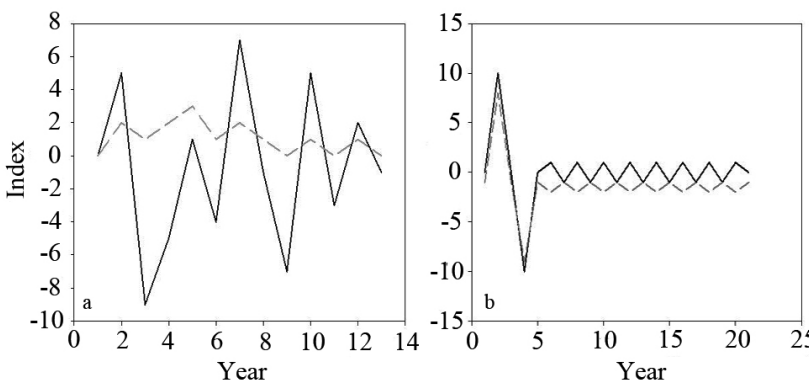

Fig. 8. Demonstrate of two conditions between Glk and r value. Notes a: High Glk value low r value; b: High r value low Glk value.

Legends - : A series chronology; - - -: B series chronology

August (A) and September (S) temperature shows strong positive influence to tree ring growth. The main rain season is from May to September. Precipitation shows negative influence on August. The possible reason is in rainfall season that extra precipitation isn't helpful to the growth of Taiwan fir. It needs high temperature than precipitation. When the summer temperature is higher, it helps better the growth of the trees which 


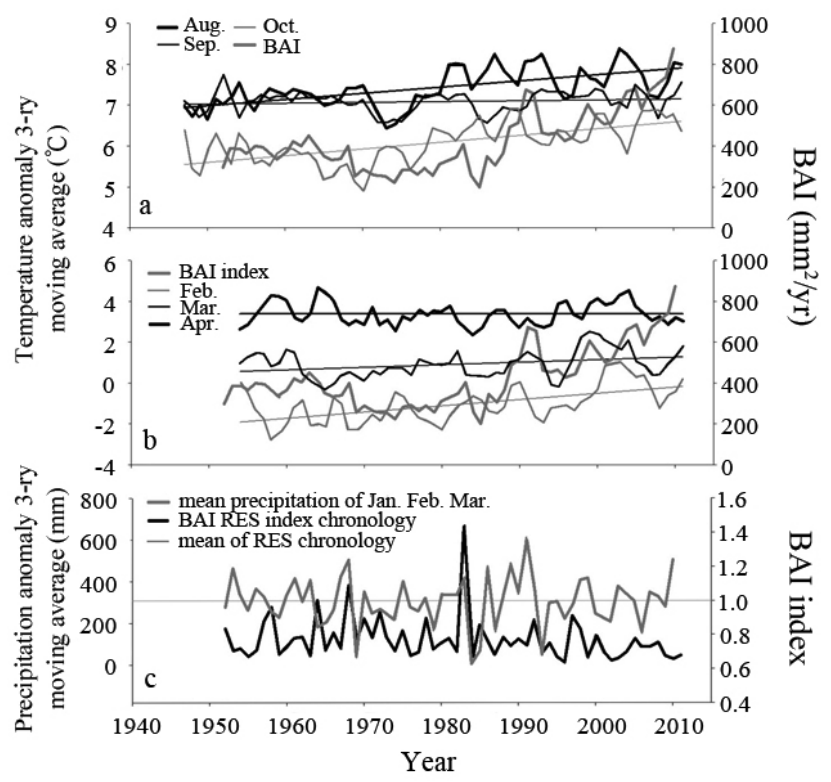

Fig. 9. Three-year moving average for temperature and precipitation anomalies calculated between 1952 and 2011.

Notes a: BAI and the temperature of Aug., Sep. and Oct.; b: BAI and the temperature of Feb., Mar. and Apr.; c: BAI RES chronology and the mean precipitation of Jan., Feb. and Mar. In graph a and b, straight lines represent the linear trends in the data

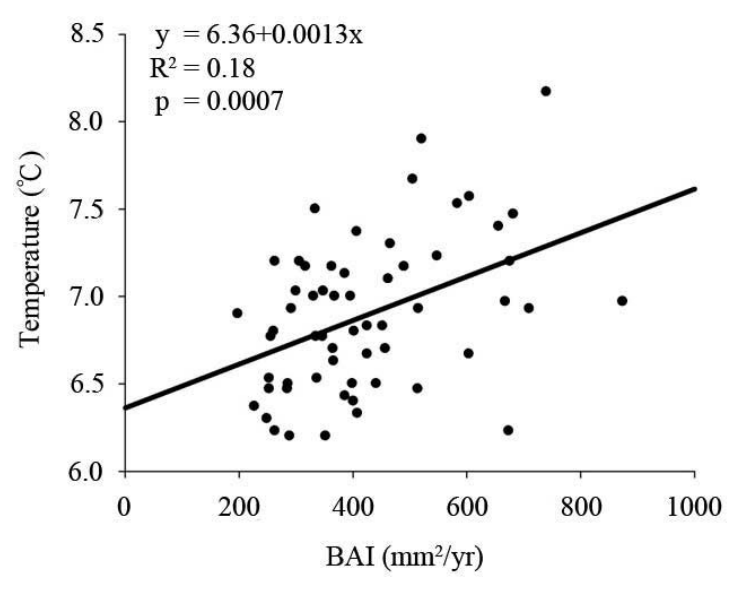

Fig. 10. The scatter plots of BAI and later summer temperature record from 1953 to 2010. The straight line represents the linear regression trends in the data.

located in the high altitude area around tree-line. (Tranquillini, 1979)

To highlight short-term trends in temperature of early spring months and later summer months we smoothed the anomaly series of the Center Weather Bureau data set for our study area with a 3-year moving average filter. A general linear trend towards temperature values is visible for these 6 months especially since the 1953s and the trends on the whole period result highly significant for February, August and October temperature (Fig. 9a, 9b). February and August presents the strongest trend (of nearly $1^{\circ} \mathrm{C}$ since 1953), whereas

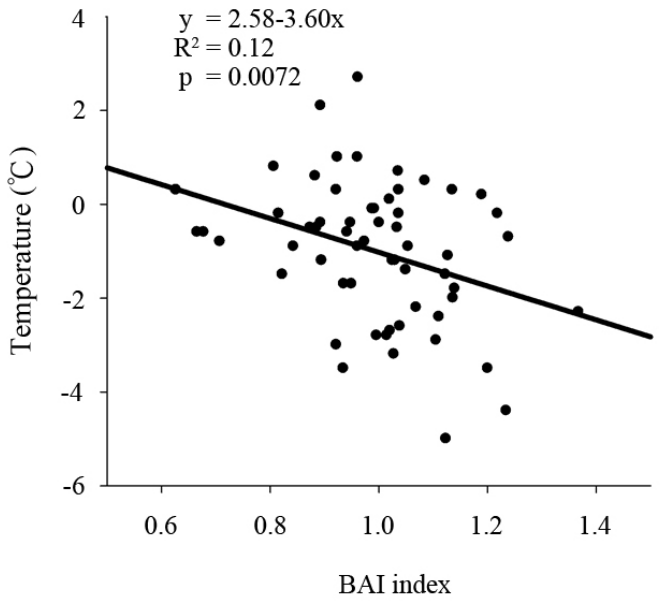

Fig. 11. The scatter plots of BAI index and February temperature record from 1953 to 2010 . The straight line represents the linear regression trends in the data.

April, Mach and September presents the weakest trend (of about $0.5^{\circ} \mathrm{C}$ ). A higher variability is noticed for precipitation, but mean precipitation of January, February and March trends on the whole period are always insignificant (Fig. 9c). The precipitation has no obvious change, but shows negative correlation with BAI index chronology.

Trees do have a positive linearly respond to high temperatures with BAI raw data $\left(\mathrm{R}^{2}=0.18, \mathrm{p}=0.0007\right)$ (Fig. $10)$ and negative respond to low temperature with BAI index chronology $\left(\mathrm{R}^{2}=0.12, \mathrm{p}=0.0072\right)$ (Fig. 11). With these responds we can reconstruct the climate before it has been record. With increasing global temperatures, we found positive influence about temperature increasing in short term influence tree growth from B.A.I raw data.

\section{REFERENCES}

Bluemle, J. P. 1999 Global warming: a geological perspective. NDGS Newsletter, 26: $1-3$

Cullen, J. T., M. P. Field and R. M. Sherrell 2001 Determination of trace elements in filtered suspended marine particulate material by sector. field HR-ICP-MS. J. Anal. Atmos. Spectrom, 16: 1307-1312

Grissino-Mayer, H. D. 2001 Evaluating crossdating accuracy: a manual and tutorial for the computer program COFECHA. Tree-Ring Research, 57(2): 205-221

Flora of Taiwan (Vol. 1) 1994. Editorial committee of the Flora of Taiwan, Taipei, Taiwan. p. 684

Holmes, R. L. 1983 Computer-assisted quality control in tree-ring dating and measurement. Tree-Ring Bullentin, 43: 69-95

King, H. B., K. J. Tan, M. J. Kan, J. L. Hwong and S. Y. Lee 1993 Genesis and classification of soils developed under Taiwan fir (Abies Kawakamii) in the western Taroko National Park. Taroko National Park Headquarters, p. 59

Kullman, L. 1998 Tree-limites and montane forests in the swedish scandes: sensitive biomoniyors of climate and variability. Ambio, 27: 312-321

Leonelli, G., P. Manuela, B, Giovanna and C. Paolo 2009 Siteaspect influence on climate sensitivity over time of a high-altitude Pinus cembra tree-ring network. Climatic Change, $\mathbf{9 6}$ 185-201 
Linares, J. C., J. J. Camarero and J. A. Carreira 2010 Competition modulates the adaptation capacity of forests to climatic stress: insights from recent growth decline and death in relict stands of the Mediterranean fir Abies pinsapo). Journal of Ecology, 98: $592-603$

Lloyd, A. H. and L. J. Graumlich 1997 Holocene dynamics of treeline forests in the Sierra Nevada. Ecology, 78: 1199-1210

MacDonald, G. M., R. A. Case and J. M. Szeicz 1998 A 538-year record of climate and treeline dynamics from the Lower Lena River Region of Northern Siberia, Russia. Arctic and Alpine Research, 30: 334-339

Pilcher, J. R. 1990 Sample preparation, cross-dating and measurement. In: Cook ER, Kairiukstis LA, (eds) Methods of dendrochronology applications in the environmental sciences. Kluwer, Dordrecht, pp. 40-50

Pumijumnong, N. and T. Wanyaphet 2006 Seasonal cambial activity and tree-ring formation of Pinus mekusii and Pinus kesiya in Northern Thailand in dependence on climate. Forest Ecology and Management, 226: 279-289

Renzo, M. and N. Paola 2001 Growth trends and dynamics in sub-alpine forest stands in the Varaita Valley (Piedmont, Italy) and their relationships with human activities and global change. Journal of Vegetation Science, 12: 219-230

Rubino, D. L. and B. C. McCarthy 2000 Dendroclimatological analysis of White Oak (Quercus alba L., Fagaceae) from an old- growth forest of southeastern Ohio, USA. Journal of the Torrey Botanical Society, 127: 240-250

Schweingruber, F. H. 2007 Wood structure and environment. Springer-Verlag, Berlin. p. 279

Serguei, A. P. 2003 New Operating Software Package for the TOF Laser Calibration System. Clas-note, 2003-014. p. 22

Speer, J. H. 2010 Fundamentals of tree-ring research. University of Arizona, Tucson, p. 333

Tranquillini, W. 1979 Physiological ecology of the alpine timberline. Springer Verlag, Berlin, p. 307

Tsou, P. S. 1998 Climate in Taiwan Mountain Area over the Past 500 Years as Revealed by Tree-ring Data. National Taiwan University Dept. of Geology master's thesis, p. 181

Walther, G. R. 2003 Plants in warmer world. Perspectives in Plant Ecology, Evolution, and Systematics, 6: 169-185

Wang. T., Q. Zhang and K. Ma 2006 Treeline dynamics in relation to climatic variability in the central Tianshan Mountains, northwestern China. Global Ecology and Biogeography, 15: 406-415

Watson, E. and B. H. Luckman 2002 The dendroclimatic signal in Douglas-fir and ponderosa pine tree-ring chronologies from the southern Canadian Cordillera. Canadian Journal of Forest Research, 32: 1858-1874

Rinntech 2009 http://www.rinntech.com/content/blogcategory/2/ 28/lang,english/ 